\title{
HAPTIC SEAT ALERT SYSTEM IN MOTORCYCLE TO REDUCE ACCIDENTS
}

\begin{abstract}
We live in a world, where speed plays a more vital role. Though speed is more important safety is considered essential. India has recorded most number of road accident per Annam about 1,35,000 annually. The country has over taken China and now has the worst road traffic accident rate worldwide. It is found that 25 percent of the total death in the road accidents are two-wheelers. The statistics shows that, one serious road accident in the country occurs every minute and 16 die on Indian roads every hour.1214 road crashes occur every day in India. Thus an alerting system is necessary to alert the motorist, in any conditions such as over speed and rash driving also to indicate the approaching of the closer rear vehicles.
\end{abstract}

The Haptic seat alert system in motorcycle is a combination of both Mechanical and Electronics operation. This system alerts the driver by producing vibration in the seat, with the help of dc vibrating motor. The system consist of Ultrasonic sensors, Electronic controlling unit and the dc vibrating motor. The Ultrasonic sensor helps in transmitting and receiving signals. The change in the signal is noted with the help of peripheral integrated circuit (PIC) this send signals to the H-Bridge motor driver. The H-Bridge motor driver controls the dc vibrating motor by using Pulse Width Modulator (PWM). The major feature in this setup is that, the right portion of the seat vibrates, only if the vehicle approach in the rear right side and the left portion of the seat vibrates only if the vehicle approach in the rear left side. This setup proves efficient and help in saving life.

\section{INTRODUCTION}

Road accidents have earned India a dubious distinction. With over 130,000 deaths annually, the country has overtaken China and now has the worst road traffic accident rate worldwide. In India alone, the death toll rose to 14 per hour in 2014 as opposed to 13 the previous year. The total number of deaths every year due to road accidents has now passed the 135,000 mark, according to the latest report of National Crime Records Bureau or NCRB.

While trucks and two-wheelers were responsible for over 40 per cent of deaths, peak traffic during the afternoon, accidents in highways and evening rush hours is the most dangerous time to be on the roads. One serious road accident in the country occurs every minute and 16 die on Indian roads every hour.1214 road crashes occur every day in India. Two wheelers account for $25 \%$ of total road crash deaths. Thus an alerting system is necessary to alert the motorist, in any conditions such as over speed and rash driving also to indicate the approaching of the closer rear vehicles.

\section{PRINCIPLE}

The Haptic alert system works on the principle of combination of both mechanical and electronics operation. Haptic alert system produces an alert to the driver by the sense of touch, in form of vibration thus ensuring alert to the rider. The vibration is produced with the help of a DC vibrating motor.

The setup consist of an Ultrasonic sensor, Electronic control unit (ECU) and DC vibrating motor. The ultrasonic sensor that is present at the rear end of the motorcycle, transmit and receives the information in the form of signals or pulses. This signal or pulses is used as an input to the Electronic control unit. The Electronic control unit (ECU) process the information and helps to govern the IC type H-bridge motor driver, which is 
typically used to control the dc vibrating motor.

This setup also consist of two more important components they are Voltage regulator 7805 and the Voltage divider. The Voltage regulator 7805 is generally used for regulating the voltage and the Voltage divider plays a key role as a step down unit, before the voltage source enters into the vibration motor.

\section{BLOCK DIAGRAM OF THE} PROPOSED SETUP:

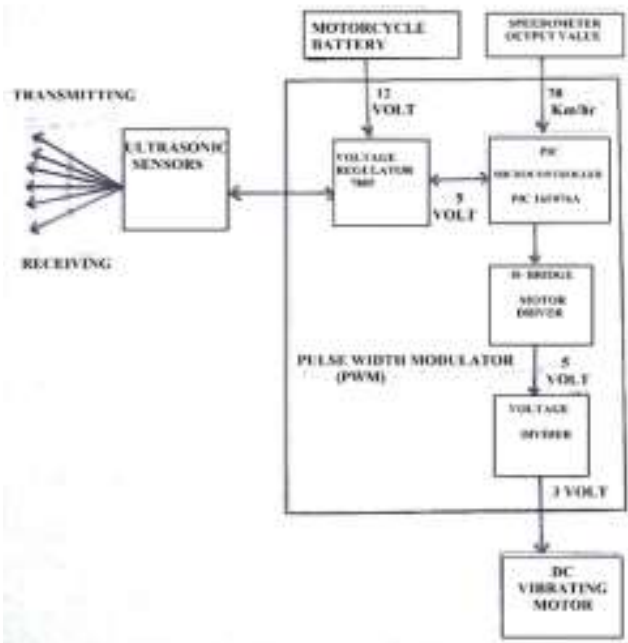

OBSTACLE ON REAR LEFT AND THE VIBRATION EXPERIENCED IN SEAT:

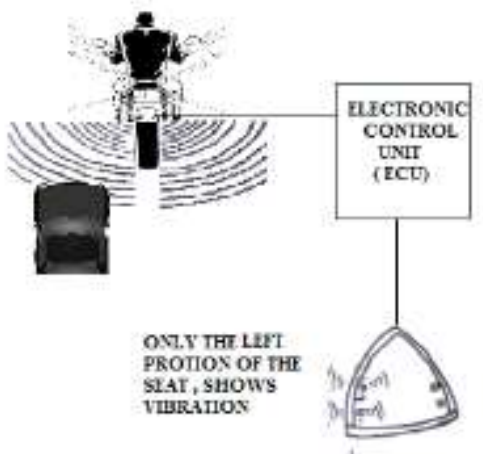

OBSTACLE ON REAR RIGHT AND THE VIBRATION EXPERIENCED IN SEAT:

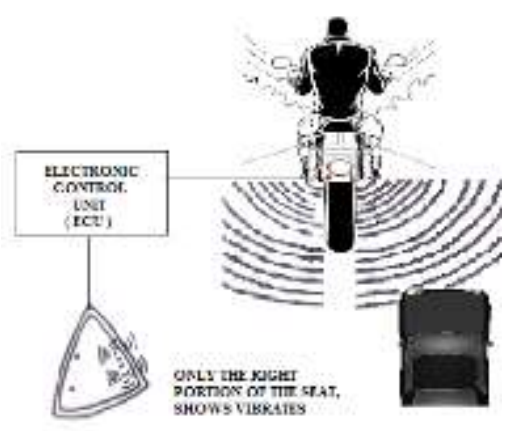

WORKING COMPONENTS:

I. Ultrasonic sensor

II. Electronic Control Unit ( ECU )

1. Voltage Regulator 7805

2. PIC Microcontroller

3. H- Bridge motor driver

4. Voltage divider

III. DC Vibrating Motor

Active Ultrasonic sensors generate highfrequency sound waves and evaluate the echo which is received back by the sensor, measuring the time interval between sending the signal and receiving the echo to determine the distance to an object.

This setup requires two Ultrasonic sensor, in which one Ultrasonic sensor is placed on the Rear right hand side and another is placed on the rear left hand side of the motorcycle. The sensors are placed in a slightly tilted angle, to ensure the coverage of rear blind region. When the speed of the vehicle crosses above or at the $70 \mathrm{Km} / \mathrm{hr}$. The Electronic control unit (ECU) receives the input from the RPM meter. It instruct the Voltage Regulator 7805 to supply power to the Ultrasonic sensor.

The Ultrasonic sensor after receiving voltage, generates transmission of the signals or pulses. The signals or pulses are transmitted and received using the same Ultrasonic sensor. The 
change in the received signal indicates the approaching of a foreign medium. The range of the Ultrasonic sensor is based on the characteristic feature of the sensor that is used.

The Second important component in this setup is the Electronic Control Unit (ECU). This helps in monitoring and controlling each and every operating components that is present in the setup. It comprises of four important parts they are

1. Peripheral integrated circuit (PIC)

2. Voltage regulator 7805

3. $\mathrm{H}$ - Bridge motor driver

4. Voltage divider

The Peripheral integrated circuit (PIC) is made up of microchip. This controls the operation of the entire system. The Integrated chip (IC) used in the Peripheral integrated circuit is PIC 16F876A. All the program that is needed for the operation of the setup is compiled into this integrated chip. This compiling process is done with the help of a PIC burner. The program is checked using some advanced software like microcontroller software (MikroC) and Proteus7 is chose to stimulate the working of the program before implementing. The integrated chip is allowed to pass a test under the Proteus7, then it is considered successful. After this, the entire PIC is ready to be installed in the setup

The next component is the Voltage regulator. A voltage regulator is designed to automatically maintain a constant voltage level. A voltage regulator may be a simple "feed-forward" design or may include negative feedback control loops. It may use an electromechanical mechanism, or electronic components. The Voltage regulator used in this setup is Voltage regulator $\mathbf{7 8 0 5}$. The source of electrical energy is obtained from Motorcycle Battery, the battery used in motorcycle has a specification of about 12 Volt. This is regulated to 5 volt which is used for the operation of the setup.
The H-Bridge motor driver is another important component in this setup. The $\mathrm{H}-$ bridge arrangement is generally used to reverse the polarity/direction of the motor, but can also be used to 'brake' the motor, where the motor comes to a sudden stop, as the motor's terminals are shorted, or to let the motor 'free run' to a stop, as the motor is effectively disconnected from the circuit. This H-Bridge motor driver receives its commands from the Peripheral integrated circuit (PIC) microcontroller. The H-Bridge motor driver helps in generating Pulse Width Modulation (PWM) that controls the vibrating effect of a DC Vibrating motor.

The final component in the Electronic control unit (ECU) is the Voltage Divider. A voltage divider is a simple circuit which turns a large voltage into a smaller one. Using just two series resistors and an input voltage, we can create an output voltage that is a fraction of the input. In this setup the voltage divider is mainly used to step down the voltage from 5 volt to 3 volt that is used for the operation of the DC Vibrating motor.

The most important component in this setup is the DC Vibrating motor. The size of the motor used, is similar to the size of the motor that is used for vibrating effect in the cell phone. Totally $4 \mathrm{dc}$ vibrating motor are used, 2 on the right foam of the seat and the remaining 2 on the left foam of the seat. This helps in generating haptic alert to the rider, when he is in danger. The important properties of DC Vibrating motor

\section{Key Features}

Body Diameter: $8 \mathrm{~mm}$ [+/- 0.1]

Body Length: $3.4 \mathrm{~mm}[+/-0.1]$

Rated Operating Voltage: $3 \mathrm{~V}$

Rated Vibration Speed: 12,000 rpm [+/- 3,000]

Typical Rated Operating Current: 70 mA

\section{WORKING}

The speed of the vehicle is monitored by the Electronic control unit. When the speed of the vehicle crosses above $70 \mathrm{~km} / \mathrm{hr}$, the Electronic 
control unit permits the Voltage Regulator to send electrical energy to the Ultrasonic sensor. The Ultrasonic sensor starts to transmit signals and also receives signals. The value of the received signal is monitored by the Peripheral integrated circuit (PIC). The change in the value, alerts the PIC microcontroller.

In case of change in the value received from the Ultrasonic sensor, the PIC microcontroller transmit signals to the H-Bridge motor driver, which in turn sends Pulse Width Modulator to the vibrating unit. A component Voltage Divider is placed in between the $\mathrm{H}$ Bridge Motor driver and the DC Vibrating motor. The use of this component is to act as a step down device. It reduces 5 volt to 3 volt, and then transmit into the DC Vibrating motor. Helping to produce vibration in the seat and alert the rider. The important part is that, the signal received from the Right Ultrasonic sensor helps to produce vibration only on the Right side of the seat and the Left Ultrasonic sensor helps to vibrate only the Left portion of the seat. This helps rider to easily identify and differentiate the direction of the rear approaching vehicle.

\section{DATA, GRAPHS AND PICTURES:}

\section{THE MOTORCYCLE DYNAMICS AND TRACK CHARACTERISTICS}

To determine the forces that act on the rider, during the rider, it is necessary first to determine the Motorcycle dynamic characteristics.

The cylinder capacity $\mathrm{V}_{\mathrm{c}}=500[\mathrm{~cm} 3]$

Maximum power $\mathrm{P}_{\max }=27.2[\mathrm{~kW}]$

Maximum torque $\mathrm{M}_{\max }=41.3[\mathrm{Nm}]$

Revolutions at maximum power $\mathrm{n}_{\mathrm{p}}=5250$ [rev/min]

Revolutions at maximum torque $\mathrm{n}_{\mathrm{m}}=4000$ [rev/min]

Gearbox type: 5 speed manual constant mesh

Gauge dimensions $\mathrm{L}=2180[\mathrm{~mm}] ; \mathrm{B}=$ 800 [mm];

$\mathrm{H}=1080[\mathrm{~mm}]$

Wheelbase Am = $1370[\mathrm{~mm}]$

Tire type: Front: 90/90 -19

Rear: $120 / 80$ - 18

Maximum speed $\mathrm{Va}_{\max }=170[\mathrm{~km} / \mathrm{h}]$

Payload $\mathrm{Q}_{\mathrm{u}}=210[\mathrm{~kg}]$

\section{Graph of traction forces vs speed}
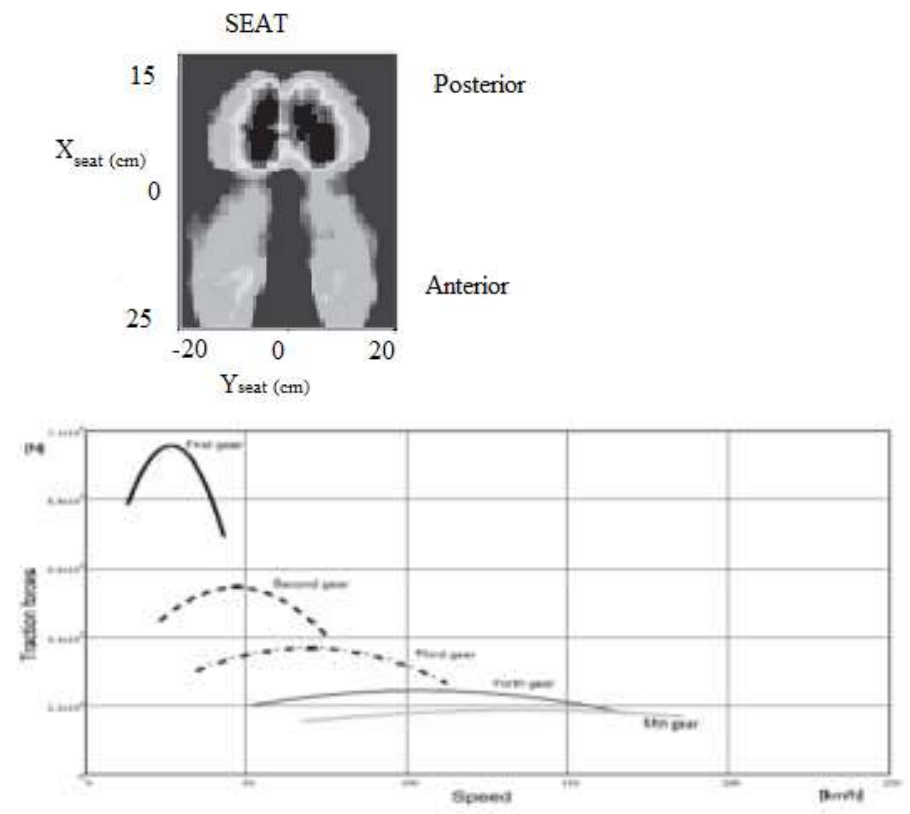

VIBRATION IN SEAT PAD

The part where we sit is called as the seat pad. The bottom part will hold our entire body and is responsible for carrying the entire weight of the body. The black and white diagram represents the area occupied by the passenger. 


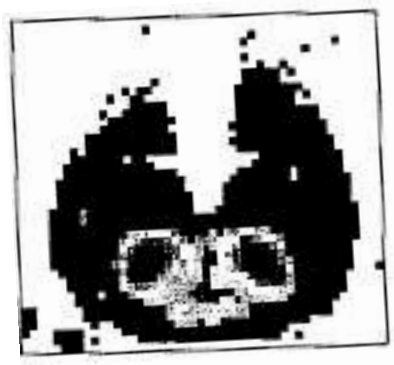

\section{seat pad visual}

This graph is an indicative of the amount of seat covered by the passenger sitting in the car seat. Those black marks indicate the amount of the human body mass that is exerted in the seat.

The vibration Hertz that is permitted for an Human Body is about $=120-140 \mathrm{~Hz}$

The vibration produced by the Vibrator is about $=200-210 \mathrm{~Hz}$.

Since the vibrators are placed within the foam, there are some loss in the frequency of vibration.

The loss in frequency of vibration is about $=$ $70-80 \mathrm{~Hz}$.

Hence the vibration experienced by the human body is about $120-130 \mathrm{~Hz}$.

This feature plays a key role in such a way that, any change in the right Ultrasonic sensor causes only the Right portion of the seat to vibrate, likewise any change in the left Ultrasonic sensor causes only the left portion of the seat to vibrate. This makes it easy for the rider to differentiate the direction of the rear approaching vehicle.

\section{STATISTICS DATA:}

Motorcyclist consume the large portion of the Pie chart, this gives information about death rate that occur during accident. The statistic data shows that $\mathbf{3 2 , 5 0 0}$ riders are dead annually due to road accidents that occur mainly due to rash driving and over speed.

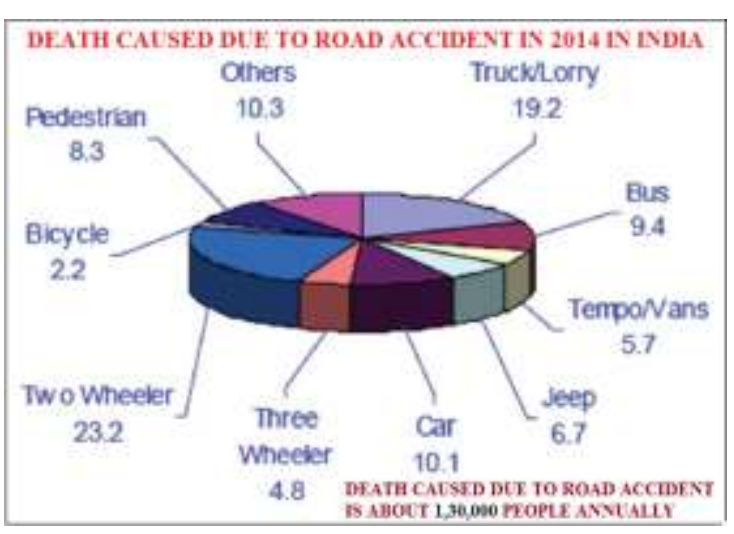

\section{USES AND ADVANTAGES}

This can be implemented in every motorcycle as it helps in

$>$ It helps to identify the direction of rear approaching vehicle.

$>$ Provides idea about the rear blind region.

$>$ Help promote safety to the highway riders.

$>$ Can lead to reduce in the rate of accident.

$>$ Cheap step up, thus can be easily implemented in all motorcycles.

$>$ Requires less space, thus can be fitted easily in seat.

\section{RESULT}

The result shows that Haptic seat alert system in motorcycle, could prove efficient by helping the rider to analyse the rear approaching vehicle. Thus making in focus on the straight road ahead and in the rear. This Haptic seat alert system in motorcycle, could help in reducing the road accident caused due to carelessness.

\section{Acknowledgement-}

We considerate it to be pleasure and privilege to express deep sense of gratitude and indebtedness towards Dr.Mohanthy, professor, Mechanical Department, St. Joseph's college of engineering, Chennai for his Constant guidance

\section{REFERENCES}

$>$ One methodology to evaluate automotive seat comfort - by Guenaelle Philippe 
$>$ Prediction of Car Seat Comfort from Human-Seat Interface Pressure Distribution - by Salvatore Demontis and Monica Giacoletto

$>$ Introduction to microcontrollers - by James Hunt (New age publishing)

$>$ Study in microcontrollers, an overview about PIC 16F876A - by Kumar Ranganathan (IIT Kanpur)

$>$ Lee J. And Ferraiuolo P.G., "Seat Comfort", SAE Technological Paper No.930105, 1993.

$>$ Ng D., Cassar T. and Gross C.M., "Evaluation of an intelligent seat", Applied Ergonomics volume 26 No 2 pp. 109-116, 1995.

$>$ Park S.J. and Chae-Bogk Kim, "The Evaluation of Seating Comfort by the Objective Measures", SAE Technological Paper No.970595, 1997.

$>$ Runkle V.A., "Benchmarking Seat Comfort" Lear Seating Corp. SAE Technical Paper No 940217.

$>$ "Measuring seat comfort", Automotive Engineering, July, 1963.

$>$ Treaster D. and Marras W.S., "Seat pressure: measurement and analysis", SAE Technical Paper No.890849, 1989.

> Yamazaki N., "Analysis of sitting comfort ability of driver's seat by contact shape", Ergonomics vol. 35 no 5/6, 677- 692, 1992.

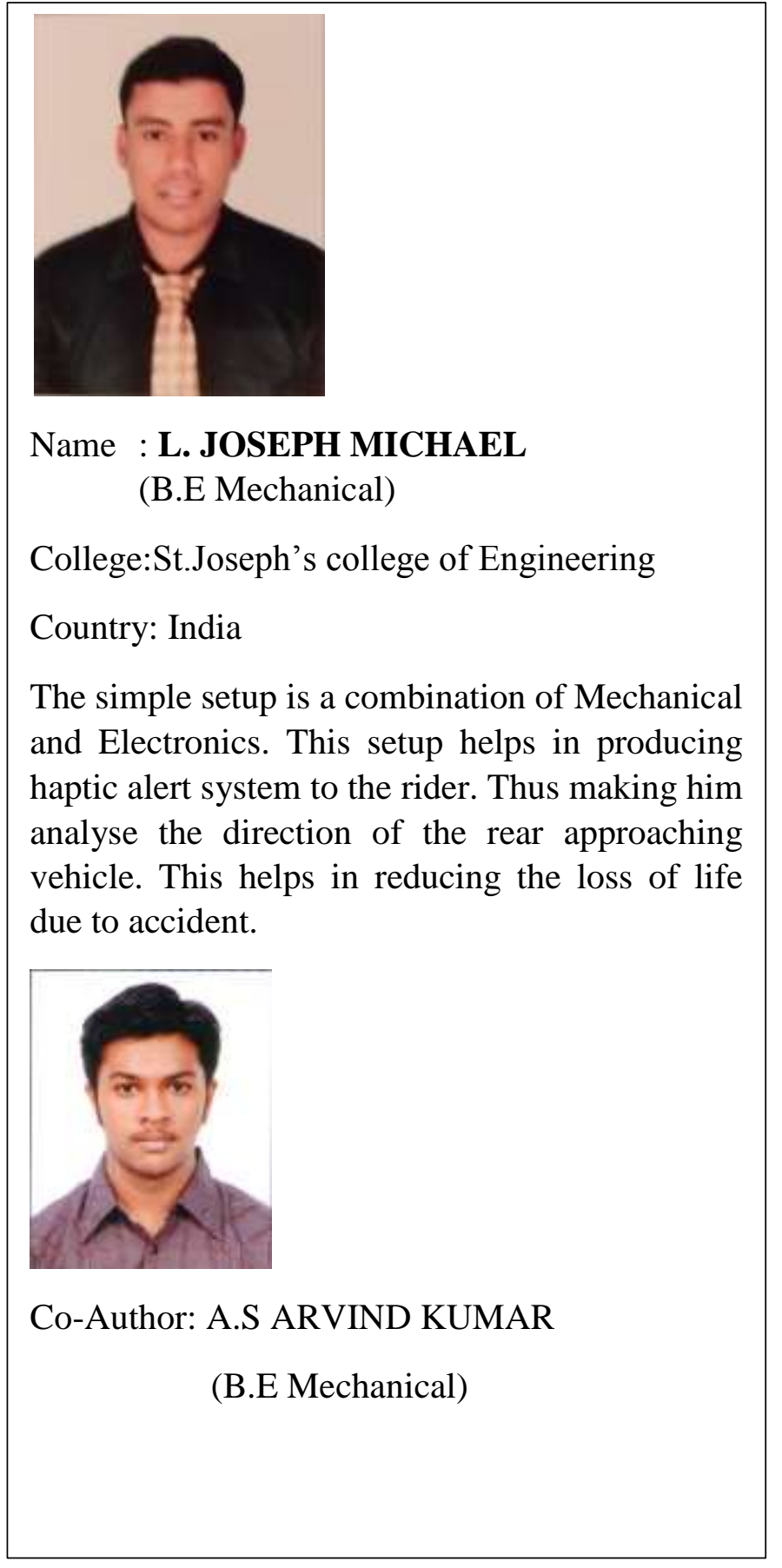

Name : L. JOSEPH MICHAEL

College:St.Joseph's college of Engineering

Country: India

The simple setup is a combination of Mechanical and Electronics. This setup helps in producing haptic alert system to the rider. Thus making him analyse the direction of the rear approaching vehicle. This helps in reducing the loss of life to accident

Co-Author: A.S ARVIND KUMAR

(B.E Mechanical) 